Nevertheless, to see conviction - and it does not necessarily need to be religious conviction - as part and parcel of someone's life is important. It can form a crucial part of how they evaluate themselves and their world and it is hard to see how one can support them without taking it into account.

Thus a person's personal conviction system is part of their personal history and identity. When George Kelly ${ }^{3}$ developed the personal construct theory he demonstrated that everyone has a personal template by which they evaluate life. If we seek to understand and respect this, we discover that we will need also to look at our own understanding because we in turn evaluate others on the basis of our own templates.

Historically, people seem to have regarded psychological processes as coming from the world outside themselves. Mental illness could be 'the work of devils' and even sexual feelings were sometimes perceived as some form of karma that entered people. Today, we have reached the opposite extreme and see that ethics, politics, law and finally religion were not delivered to us by some external agency but were created by ourselves.

With this in mind we can explore the spiritual pilgrimage of our patients with them without imposing on them preconceptions of our own. It is an interesting journey because everyone's pilgrimage is different, and without knowing their story you will not understand where they are in the present, nor what will be the next step in their future.

Those who study religious and ideological traditions will find nuggets of great wisdom in all of them and this understanding is enhanced the more one knows the cultural and historical background in which they originated. We are all on a learning curve but I hope that it will not be long before there are consultants who have a vivid knowledge of religion and ideology from a psychological perspective and who will enhance our ability to understand the individual patients in our care more completely.

The more one tries to understand the depths of other people, the more one deepens one's own understanding and this may help alleviate that hidden isolation, loneliness and even despair that comes from never being properly listened to, or at any rate to find someone who at least tries to understand.

1 Comte-Sponville A. The Little Book of Atheist Spirituality (transl N Huston). Penguin, 2007.

2 Dein S, Cook CCH, Powell A, Eagger S. Religion, spirituality and mental health. Psychiatrist 2010; 34: 63-4.

3 Kelly GA. The Psychology of Personal Constructs. Norton, 1955.

John Edmondson, Consultant in Child and Adolescent Psychiatry, Lincolnshire, email: john.edmondson5@btopenworld.com

doi: $10.1192 / \mathrm{pb} .34 .8 .355 \mathrm{~b}$

\section{When to use DoLS? A further complication}

Shah \& Heginbotham ${ }^{1}$ describe a number of issues relating to the Deprivation of Liberty Safeguards (DoLS) of the Mental Capacity Act. A recent court case ${ }^{2}$ appears to complicate matters further. The defendant was a 55-year-old lady with 'a significant impairment in intellectual functioning as a consequence of a learning disability' who developed an endometrial adenocarcinoma. She required major surgery if her life was to be saved. It was agreed that she lacked the capacity to make decisions about her healthcare and treatment.
She also suffered from hospital and needle phobias. Attempts to explain the need for surgery to her had failed and on occasions she refused to attend hospital for treatment (even when she had initially agreed).

The judge agreed the defendant could be sedated to ensure that she attended hospital for the operation and did not 'leave it prematurely after the operation had taken place'. She would 'be given analgesic medication which would have a sedative effect on her, thereby rendering it unlikely that she would be able to abscond. However, it might be necessary to use force as a last resort to ensure that she returned to her hospital bed'.

The judge then said 'In my judgment . . . it will be necessary to detain [the defendant] in hospital during the period of post-operative recovery. After mature consideration, the Official Solicitor, on [the defendant's] behalf, came to the view that it was not necessary to invoke the Deprivation of Liberty Provisions under Schedule 1 of the Act. I agree with that analysis. If it is in [the defendant's] interests (as it plainly is) to have the operation, it is plainly in her interests to recover appropriately from it'.

Given that it was planned, if necessary, to use sedation and/or force to prevent this patient leaving hospital, she was clearly to be deprived of her liberty. The court determined that because the patient lacked capacity and it was in her best interest (two necessary criteria for the use of DoLS), the DoLS were unnecessary.

Other articles in The Psychiatrist ${ }^{1,2,4}$ discuss the problems surrounding the definition of deprivation of liberty and the interface between the DoLS provisions of the Mental Capacity Act and the Mental Health Act. It now seems there is a further difficulty in determining whether the DoLS provisions are needed even if there is clear deprivation of liberty.

1 Shah A, Heginbotham C. Newly introduced deprivation of liberty safeguards: anomalies and concerns. Psychiatrist 2010; 34: 243-5.

2 DH NHS Foundation Trust v. PS (by her litigation friend the Official Solicitor) [2010] All ER (D) 275 (May).

3 Selmes T, Robinson J, Mills E, Branton T, Barlow J. Prevalence of deprivation of liberty: a survey of in-patient services. Psychiatrist 2010; 34: $221-5$

4 Cairns R, Richardson G, Hotopf M. Deprivation of liberty: Mental Capacity Act safeguards versus the Mental Health Act. Psychiatrist 2010; 34: 246-7.

Tony S. Zigmond, Psychiatrist, Royal College of Psychiatrists' lead on mental health legislation, Leeds, email: azigmond@doctors.org.uk doi: $10.1192 / p b .34 .8 .356$

\section{Doctors are not adhering to General Medical Council prescribing guidelines}

In light of recent media coverage of the General Medical Council (GMC) suspension of Adam Osborne, ${ }^{1}$ we became interested in the issue of doctors prescribing to non-patients: friends, family and self. The GMC recommends that doctors do not self-prescribe or prescribe to family and friends, except in an emergency. ${ }^{2}$

We audited prescribing practices among doctors working in London to determine whether GMC guidelines are being followed. We composed a 13-question online questionnaire 